\title{
Immunosuppression of xenograft rejection in porcine kidney PK15 cells by porcine IL-18
}

\author{
Yun Sil Choi ${ }^{1,2}$, Young Kwan $\mathrm{Kim}^{1,2}$, \\ Jung Hyun Shim ${ }^{3}$, Eun Mi Kim ${ }^{4}$, \\ Hyung Sik Kang ${ }^{4}$, Do Young Yoon ${ }^{5}$, \\ Yoshihiro Muneta ${ }^{6}$ and Pyung Keun Myung ${ }^{1,2,7}$ \\ ${ }^{1}$ Clinical Biochemistry Laboratory \\ Department of Pharmacy, College of Pharmacy \\ ${ }^{2}$ Research Center for Transgenic Cloned Pigs \\ Chungnam National University \\ Daejeon 305-764, Korea \\ ${ }^{3}$ Hormel Institute \\ University of Minnesota \\ Austin, Minnesota 55912, USA \\ ${ }^{4}$ Division of Life Science and Technology \\ Chunnam National University \\ Gwangju 501-757, Korea \\ ${ }^{5}$ Department of Bioscience and Biotechnology \\ Konkuk University \\ Seoul 143-701 \\ ${ }^{6}$ National Institute of Animal Health \\ Tsukuba, Ibaraki 305-0856, Japan \\ ${ }^{7}$ Corresponding author: Tel, 82-42-821-5929; \\ Fax, 82-42-823-6566; E-mail, pyung@cnu.ac.kr
}

Accepted 12 October 2006

Abbreviations: EC, endothelial cell; Ig, immunoglobulin; MLR, mixed lymphocyte reaction; MTS, microculture tetrazolium assay

\begin{abstract}
Xenotransplantation, the transplantation of cells, tissues or organs between individuals of different species, would resolve the current shortage of organs, but rejection remains the major hurdle to successful xenotransplantation. In the present study, we analyzed mixed lymphocyte reactions (MLRs) and used ${ }^{51} \mathrm{Cr}$ release assays in order to identify the proliferation and expansion of mouse $\mathrm{CD8}^{+}$cytotoxic $\mathrm{T}$ lymphocyte cells against PK15, PK15/plL-18 or PK15/mlL-18 cells. In addition, we identified $T$ cell populations in mouse splenocytes and lymph node cells using two-color flow cytometry. It was found that the $\mathrm{CD}^{+} \mathrm{T}$ cells of xenograft recipients proliferated extensively and that the survival rates of populations of PK15/mIL-18 or PK15/pIL-18 cells were higher than untransfected
\end{abstract}

controls. Moreover, $\mathrm{CD}^{+} \mathrm{T}$ cells were increased in mice injected with PK15 cells or PK15/plL-18 cells but PK15/pIL-18 cell numbers were lower in lymph nodes than untransfected controls. $C D 8^{+} T$ cells numbers were reduced in the lymph nodes of PK15/pIL-18 injected mice. These results suggest that porcine IL-18 regulates anti-pig cellular rejection in C57BL/6 mice.

Keywords: CD8-positive T lymphocytes; graft rejection; interleukin-18; kidney; pig

\section{Introduction}

Xenotransplantation - the transplantation of cells, tissues or organs between individuals of different species - offers the possibility of overcoming current organ shortages, and is a potential avenue for the application of new technologies, such as, genetic engineering, cloning, and the rational design of therapeutics (Cascalho and Platt, 2001).

Human anti-porcine T-cell response resembles allogenic response, in which human $T$ cells recognize porcine major histocompatibility complex (MHC) class II antigens through the direct pathway. It was recently reported that T-cell-mediated xenoimmune response is $\mathrm{CD}^{+}{ }^{+}$T-cell-dependent. The activation of $\mathrm{CD}^{+} \mathrm{T}$ cells by immunogenic xenopeptides results in the local secretions of various cytokines, including IL-2, within xenografts. These cytokines further induce the differentiation of activated $\mathrm{CD} 8^{+} \mathrm{T}$ cells into CTLs that can kill various xenogenic and syngenic target cells in a nonspecific manner. Also, human $\mathrm{CD}^{+} \mathrm{CTL}$ clones elicit an immune response to pig antigens introduced into humans as food (Hartig et al., 2000).

The potential of xenotransplantation for clinical applications requires the overcoming of the barriers of humoral and cellular rejection, through strategies based on immune suppression or tolerance induction (Barth et al., 2003). Various cytokines, including IL-1 $\beta$, IL-2, IL-4, IL-10, IL-12p40, IFN- $\gamma$, and TNF- $\alpha$ have been recently reported to play important roles in both host and donor cell activations during xenotransplantation, and interleukin-18 (IL-18) is also expected to minimize host rejection during xenotransplantation.

$\mathrm{IL}-18$ is a novel cytokine (also known as IFN- $\gamma$ inducing factor) because of its ability to induce IFN- $\gamma$ 
production by $\mathrm{T}$ helper 1 (Th1) cells. Moreover, it was found that IL-18 has a variety of biological function, including the stimulation of the proliferation of activated $T$ cells, the enhancement of the activities of NK cells, the induction of granulocytemacrophage colony-stimulating factor by activated $T$ cells, and the stimulation of Fas $L$ mediated cytotoxicity by NK cells and T cells (Muneta et al., 2002). In addition, it has been reported that IL-1 $\beta$ converting enzyme (ICE) is responsible for processing this precursor protein to a biologically active form. Activated macrophages also produce many other kinds of cytokines concerned with host defenses against pathogens and tissue injury. More interestingly, IL-18 and IL-12 have a synergistic effect on the stimulation of IFN- $\gamma$ production by $\mathrm{T}$ cells (Nakanishi et al., 2001), and since IL-18 is an important cytokine involved in the development of protective immune responses, it may be clinically useful as an anti-microbial and/or anti tumor agent (Muneta et al., 2002).

IL-18 enhances Fas $L$ expression and induces apoptosis in Fas-expressing cells (Ohtsuki et al., 1997). Moreover, endogenous IL-18 modulates the immune escape of murine melanoma cells by intracellular reactive oxygen intermediates (ROI) and Fas-ligand expression (Cho et al., 2002). Besides GVHD, the major complication of allogenic bone marrow transplantation; the timing of IL-18 activation or blockade is crucial for the avoidance of GVHD development. For example, the early administration of IL-18 prevented GVHD mortality in mice whereas an IL-18 blockade increased the incidence of GVHD (Holler, 2002). This could be explained by early activation of host macrophages and subsequent Fas-mediated donor cell apoptosis.

The examination of the role of IL-18 in the pig is essential for understanding porcine protective immune responses and disease development. The amino acid sequence deduced from porcine IL-18 cDNA encodes a 192 amino-acid polypeptide that exhibits $92,90,81$ and $71 \%$ similarity to those of horse, dog, human and rodent, respectively (Oem et al., 2000). Also, an analysis of IL-18 expression in different organs of piglets demonstrated that IL-18 mRNA is weakly expressed in kidney and lung, but highly and constitutively expressed in spleen, mesenteric lymph nodes, and intestine (Oem et al., 2000).

In the present study, we investigated the immunobiological effects of IL-18 genes on xenograft PK15 cells rejection in $\mathrm{C} 57 \mathrm{BL} / 6$ mice.

\section{Materials and Methods}

\section{Animals}

Female C57BL/6 mice were purchased from Dae Han Bio Link (Korea). Mice between 6-and 8-weeks of age were housed in sterilized microisolator cages and received filtered water and normal chow.

\section{Cell culture}

Porcine kidney PK15 epithelial cells were obtained from the American Type Culture Collection (Rockville, MD). Cells were cultured in Eagle's Minimum Essential Media (MEM)(ATCC, Manassas, VA) containing $10 \%$ fetal bovine serum (GIBCO) and maintained at $37^{\circ} \mathrm{C}$ in a $5 \% \mathrm{CO}_{2}$ incubator.

\section{Plasmid construct of porcine interleukin-18}

The vectors pVL1392 and pAcGPB containing porcine precursor IL-18 (plL-18) and mature IL-18 (mIL-18) cDNA, respectively, were kindly provided by Dr Yoshihiro MT (National Institute of Animal Health, Japan) (Muneta et al., 2002). To construct a mammalian expression vector, porcine plL-18 and mIL-18 were excised from pVL1392 using Bg/llEcoRI and from pAcGPB using BamHI-Pst and ligated into $p C M V$-taq vector (Stratagene). The resulting plasmids were designated pCMV-Taq2B/ pIL-18 and pCMV-Taq2B/mIL-18.

\section{Stable transfection}

PK15 cells were seeded into 6-well tissue culture plates (Falcon 3046) for 18 to $24 \mathrm{~h}$ before transfection and grown to 60 to $80 \%$ confluence. pCMVTaq2B/plL-18 or pCMV-Taq2B/mIL-18 (5 $\mu \mathrm{g}$ in $100 \mu \mathrm{l}$ of serum-free medium) were mixed with an equal volume of serum-free medium containing $10 \mu$ of Metafectene reagent (Biontex, Korea), and incubated at room temperature for $25 \mathrm{~min}$, and then added to PK15 cells. Cells were incubated for $3 \mathrm{~h}$, and then $1 \mathrm{ml}$ of medium containing $10 \%$ FBS was added. At confluence, cells were seeded in 6-well plates at 2 $\times 10^{5}$ cells/well treated with $0.125 \%$ trypsin-EDTA and incubated for additional $24 \mathrm{~h}$ before applying Geneticin (GIBCO) to select stable transfectants. We named these stable cell lines PK15/pIL-18 and PK15/mIL-18.

\section{Isolation of total RNA}

Total RNAs were extracted from PK15/pIL-18 and PK15/mIL-18 transfectants using the acid guanidinium thiocyanate-phenol-chloroform extraction method (Chomczynski and Sacchi, 1987). Stable transfectants were lysed in $1 \mathrm{ml}$ of extraction buffer (4 M 
guanidine solution, $25 \mathrm{mM}$ sodium citrate, $\mathrm{pH} 7.0$, $0.5 \%$ sodium $N$-lauroyl sarcosinate, $0.1 \mathrm{M} 2$-mercaptoethanol). A one-tenth volume of chloroform/phenol (49:1) was added to the samples, and they were then incubated on ice for $5 \mathrm{~min}$ and centrifuged at $12,000 \mathrm{rpm}$ for $30 \mathrm{~min}$ at $4^{\circ} \mathrm{C}$. RNA contained in the upper aqueous phase was collected, precipitated with an equal volume of isopropanol, and washed twice in $70 \% \mathrm{EtOH}$. RNA pellets so obtained were dissolved in distilled water, quantified by O.D $260 / 280$ and visualized in ethidium bromide-stained agarose gels.

\section{Reverse transcription-polymerase chain reaction (RT-PCR)}

RT-PCR was carried out to detect the expression of porcine precursor IL-18 and mature IL-18 from total RNA isolated from stable transfectants. cDNA was synthesized from total RNA in a $50 \mu$ reaction volume containing $5 \mu \mathrm{l} 10 \times$ first-strand buffer, $1 \mu \mathrm{l}$ of RNase block ribonuclease inhibitor (Promega, Madison, WI), $2 \mu \mathrm{l}$ of $100 \mathrm{mM}$ dNTPs, and $1 \mu \mathrm{l}$ of Moloney murine leukemia virus reverse transcriptase (Stratagene, La Jolla, CA), and the mixture was then incubated at $37^{\circ} \mathrm{C}$ for $1 \mathrm{~h}$. The resulting cDNA was amplified using the following PCR conditions (35 cycles of $1 \mathrm{~min}$ at $95^{\circ} \mathrm{C}, 1 \mathrm{~min}$ at $57^{\circ} \mathrm{C}$ and $90 \mathrm{~s}$ at $72^{\circ} \mathrm{C}$ ). The PCR products obtained were analyzed on $1 \%$ agarose gels. $\beta$-Actin was chosen as the house-keeping gene. The primers used were as follows: $\beta$-actin: 5'-GCCATGTACGTTGCTATCCAG GCTG-3' (forward), 5'-AGCCGTGGCCATCTCTTG CTCGAAG-3' (reverse), T3 promoter: 5'-CCCTTTA GTGAGGGTTAATT-3' (forward), T7 promoter: 5'-TT AATACGACTCACTATGGG-3' (forward), porcine IL-18: 5'-ATGAAGACTCAAACTGTATCT-3' (reverse).

\section{Real-time quantitative RT-PCR}

Total RNA was extracted from mouse liver, kidney, spleen, intestine, thymus, lung and lymph nodes using TRIzol reagent (Invitrogen, Carlsbad, CA). Extracted total RNAs were reverse transcribed to synthesize $75 \mu$ l of cDNA. The following $20 \mu$ l quantitative PCR (QPCR) contained $2 \mu \mathrm{l}$ of CDNA, $10 \mu \mathrm{l}$ of $2 \times$ SYBR Green master mix (Qiagen), and 10 pmole of sense and antisense primer. Real-time PCR was performed using a Rotor Gene 2000 PCR machine (Corbett Research). The primers used were as follows: $\beta$-actin: 5'-TCACCCACATGTGCCCATC TACGA-3' (forward), 5'-CAGGGGAACCGCTCATT GCCAATGG-3' 3 (reverse), mouse IL-18: 5'-ACTG TACAACCGCAGTAATAC-3' (forward), 5'-AGTGAA CATTACAGATTTATCCC-3' (reverse), mouse IFN- $\gamma$ : 5'-TTGGATATCTGGAGGAACTG-3' (forward), 5'-C CTCAAACTTGGCAATACTC-3' (reverse). For each reaction, the polymerase was activated by preincubation at $95^{\circ} \mathrm{C}$ for $5 \mathrm{~min}$, and amplification was performed over 30 cycles of $95^{\circ} \mathrm{C}$ for $20 \mathrm{~s}, 56^{\circ} \mathrm{C}$ for $20 \mathrm{~s}$ and $72^{\circ} \mathrm{C}$ for $40 \mathrm{~s}$. The results are presented as threshold cycle values (Ct values), which are estimates of amplification cycle numbers when the fluorescence exceeded a specified threshold value (Lorant et al., 2003). All tissue samples were run in duplicates for cDNA synthesis. Results were analyzed using Rotor-Gene analysis software V6.0.

\section{One-way mixed leukocyte reaction}

The proliferation of splenocytes responding to allogenic stimuli was determined using a one-way mixed leukocyte reaction (Hill et al., 2001). Stimulator cells (Stable transfectants or wild PK15) were treated at 8 $\times 10^{6}$ cells $/ \mathrm{ml}$ with $50 \mu \mathrm{g} / \mathrm{ml}$ mitomycin C. Responding cells (mouse spleen cells) were added at $8 \times$ $10^{6}$ cells $/ \mathrm{ml}$ with recombinant mouse IL-2 $(10 \mu \mathrm{g} / \mathrm{ml})$ in a final volume $200 \mu \mathrm{l}$. Cells were plated in 96 -well round bottle plates (Corning Glassware, Corning, NY) with $4 \times 10^{5}$ lymphocytes and $4 \times 10^{5}$ PK15 cells per well. Co-cultures were performed over 3 days at $37^{\circ} \mathrm{C}$ in a humidified $5 \% \mathrm{CO}_{2}$ incubator. After $3 \mathrm{hr}$ treatment in microculture tetrazolium assays (MTS), supernatants were collected to quantify splenocyte proliferation. Microculture tetrazolium (MTS) and phenazine methosulphate (PMS) were mixed at a ratio of 39:1 and added at $50 \mu /$ well in 96-well round bottle plates. Plates were then incubated for $3 \mathrm{~h}$ at $37^{\circ} \mathrm{C}$ in a $\mathrm{CO}_{2}$ incubator, and enzyme activities were determined by measuring absorbance at $490 \mathrm{~nm}$ using an ELISA reader (Molecular Device, Hercules).

\section{${ }^{51} \mathrm{Cr}$ release assay: in vitro cytotoxic assay}

The cytotoxic functions of $T$ cells were analyzed using ${ }^{51} \mathrm{Cr}$ release assays. Mouse spleen cells, injected with PK15 or treated with recombinant mouse IL-18 were activated with recombinant human IL-2 in complete medium for $48 \mathrm{~h}$ before the test. Transfected PK15 cells or untransfected target cells $\left(1 \times 10^{6}\right.$ cells $\left./ \mathrm{ml}\right)$ were labeled for $120 \mathrm{~min}$ with $0.1 \mathrm{mCi}$ of $\mathrm{Na}_{2}{ }^{51} \mathrm{CrO}_{4}$ (DuPont-NEN, LesUlis, France), washed three times in RPMI 1640 supplemented with $10 \% \mathrm{FBS}$, resuspended in $3 \mathrm{ml}$ of the same medium and incubated for $96 \mathrm{~h}$ at $37^{\circ} \mathrm{C}$. Stable transfectants were then washed twice in complete medium and applied to mouse spleen cells at a ratio of $1: 200,1: 20$ or $1: 10$ in final volume of $200 \mu \mathrm{l}$. After $4 \mathrm{~h}$ of incubation at $37^{\circ} \mathrm{C}, 100 \mu \mathrm{l}$ of supernatant was collected from each well and counted in a $\beta$-counter (Wallac, Gaithersburg, MD). Spontaneous ${ }^{51} \mathrm{Cr}$-release (spont. cpm) was measured in wells containing only target cells. Maximum ${ }^{51} \mathrm{Cr}$ release 
(max. cpm) was determined by adding $100 \mu \mathrm{l}$ of $1 \%$ Triton X-100 (Sigma) to wells containing labeled wild PK15 cells. Assays were performed in triplicate and results are expressed as ${ }^{51} \mathrm{Cr}$-release percentages and were calculated using the formula:

$\%$ of ${ }^{51} \mathrm{Cr}$ release $=100 \times[(\mathrm{cpm}$ of test sample $\mathrm{cpm}$ of spontaneous lysis)/(cpm of maximum control - cpm of spontaneous lysis)]

\section{Transplantation of PK15 and PK15/plL-18 cells}

Mice underwent transplantation according as described previously (Zhan et al., 2003). Recipient mice were injected intravenously using a $1 \mathrm{ml}$ syringe with $2 \times 10^{6}$ PK15 cells or PK15/plL-18 cells in $0.5 \mathrm{ml}$ PBS.

\section{Flow cytometric assays}

Spleens, lymph nodes, thymus glands were removed aseptically from mice immunized with PK15 cells or PK15/pIL-18 and crushed with a $40 \mu \mathrm{m}$ Nylon cell strainers (Falcon, San Jose, CA) in RPMI 1640 culture medium. These lymphocytes were separated by centrifuge at $1,700 \mathrm{rpm}$. Splenocytes $\left(2 \times 10^{6}\right.$ cells $\left./ \mathrm{ml}\right)$ were added to $5 \mathrm{ml}$ of erythrocyte lysis buffer (Sigma, St. Louis, MO). Fluorescein isothiocyanate (FITC)-conjugated monoclonal antibodies (Mo-Abs) to mouse CD3, CD4 and B220 and $\mathrm{PE}$-conjugated MoAbs to mouse CD3 and CD8 were purchased from Becton Dickinson Pharmingen (San Diego, CA). Cells were washed twice with ice cold FACS buffer (PBS buffer, 1\% fetal calf serum, 0.05\% sodium azide) after each step. Cells were fixed with $1 \%$ paraformaldehyde in PBS buffer and subse- quently analyzed on a FACSCalibur flow cytometer (Becton Dickinson, San Jose). Dead cells and debris were excluded by forward side scatter gating.

\section{Results}

Construction of porcine IL-18 expression using a mammalian expression vector system

Porcine cDNA contains an open reading frame of 579 bp and encodes a 192 amino acid precursor protein, which does not contain a typical hydrophobic signal peptide. Therefore, it has a potential ICE cleavage site after amino acid residue 35 (aspartic acid) (Muneta et al., 2002). The resulting $474 \mathrm{bp}$ cDNA is thought to be the mature form of porcine IL-18. Porcine IL-18 vector was kindly provided by Dr Yoshihiro MT (National Institute of Animal Health, Japan) (Muneta et al., 2002). It was used to transfer pVL1392 or pAcGPB containing porcine precursor IL-18 or mature IL-18 cDNA to pCMV-Taq 2B of mammalian expression vector (Figure $1 \mathrm{~A})$. The resulting plasmids were named pCMV-taq 2B/pIL-18 and pCMV-taq 2B/mIL-18. Then, we analyzed porcine plL-18 or mIL-18 fragments levels produced by digesting vectors with restriction enzymes using agarose gel. Porcine plL-18 and mIL-18 were identified as 579bp and 474 bp bands, respectively (Figure 1B).

\section{Specific expression of porcine IL-18 by transfected PK15 cells}

The porcine kidney epithelial cell line PK15 was transfected with porcine precursor IL-18 (plL-18) or
A

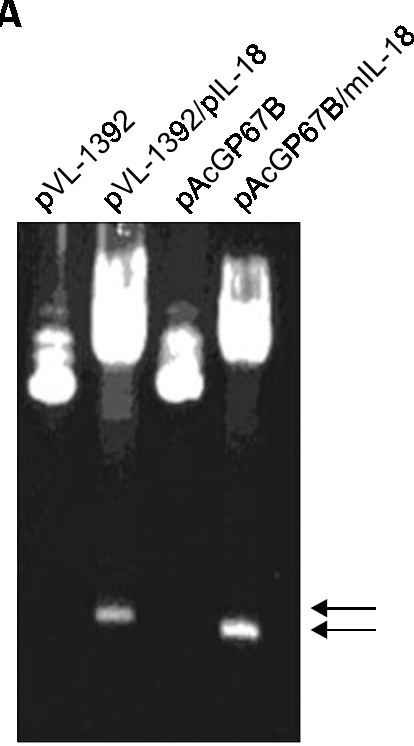

B

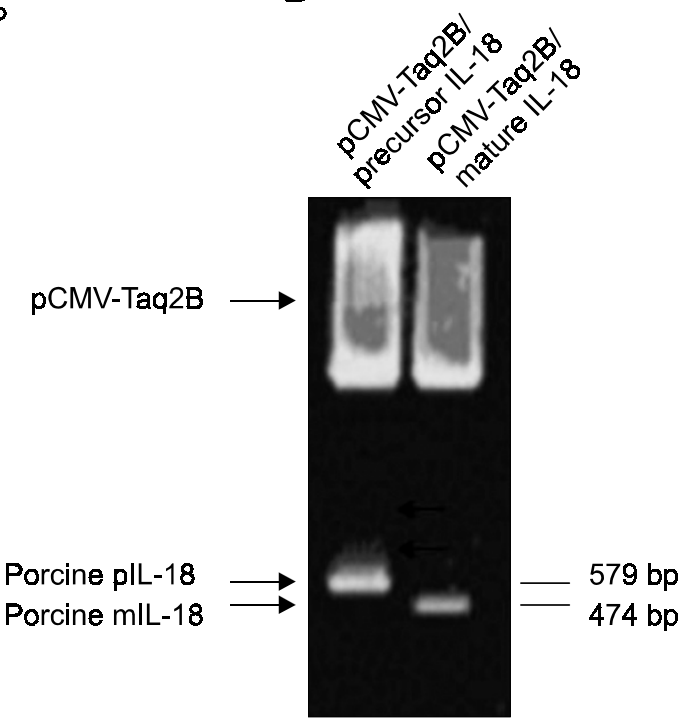

Figure 1. Agarose gel electrophoresis showing restriction enzyme digestions of porcine precursor IL-18 or mature IL-18. The plasmids were cleaved using the following enzymes. (A) Vector pVL1392 and pAcGPB containing porcine precursor IL-18 and mature IL-18 cDNA were cleaved by Bg/ll/EcoRI and BamHI/Pstl fragment and each smaller fragment were ligated into $\mathrm{PCMV}$-Taq $2 \mathrm{~B}$ vector. (B) Porcine precursor IL-18 and mature IL-18 constructs with pCMV-Taq 2B were digested using EcoRI/ Notl and BamH1/ Pst I. 
mature IL-18 (mIL-18) cDNA in an expression vector (pCMV-Taq 2B) containing a neomycin resistance gene. After selection with G418 sulfate, several clones were isolated by RT-PCR (Figure 2). We obtained single bands for the porcine IL-18 gene as a $474 \mathrm{bp}$ fragment for mature IL-18 and as a $579 \mathrm{bp}$ fragment for precursor IL-18. These specific PCR bands were not found in untransfected PK15 cells (Figure 2, lane 1). It was recently reported that the IL-18 transcript is weakly expressed in the porcine kidney and lung, and that it is highly expressed in the spleen and lymph nodes (Oem et al., 2000). pCMV-Taq2B (MOCK) vector transfectant was used as a negative control (Figure 2, lane 2 ). The single $\beta$-actin mRNA band at 538 bp was used as a control. One clone was chosen for subsequent experiments, i.e., either PK15/pIL-18 or PK15/mIL-18 (Figure 2, lane 3,4).

\section{Effect of porcine IL-18 expression on the responses of donor PK15 cells in primary Mixed Lymphocyte Reaction (MLR)}

MLR is an in vitro system for assaying $\mathrm{T}_{\mathrm{H}}$-cell proliferation due to a cell-mediated response. In one-way MLR, the unresponsive population provides stimulator cells, which express alloantigens foreign to responder T cells. PK15 cells, stimulator cells, were treated with mitomycin C. Mouse splenocytes were harvested from IL-18 treated recipients 28 days after transplantation and were used as responders during MLR. Splenocytes proliferations to PK15 cells were assessed using MTS assays. Tetrazolium salts produced soluble formazan salt via the succinatetetrazolium reductase system in live cell mito-

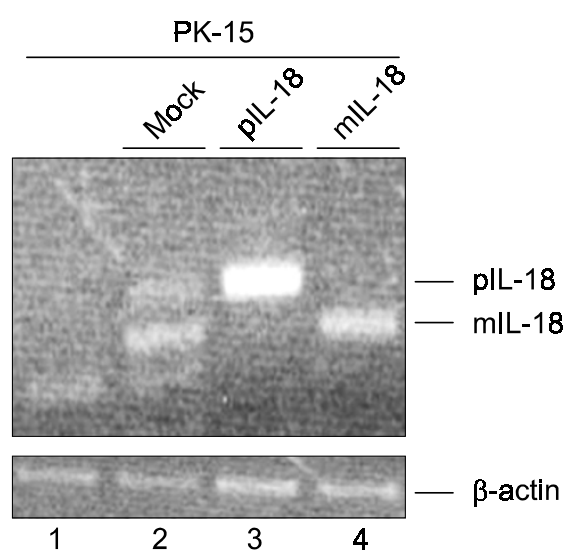

Figure 2. Analysis of porcine IL-18 expression in a stable transfected cell line and in parental PK-15 cells. Precursor and mature IL-18 of porcine in transfectants were detected by RT-PCR using total RNA and appropriate combined primer sets. Lane 1, PK15 cells; Lane 2, negative control cells; Lane 3, PK15/plL-18 transfected cells; Lane 4-5, PK15/mlL-18 transfectants. chondria. Cell proliferation was no different among mouse responder cells. Within 24-48 h, responder $\mathrm{T}$ cells started dividing in response to the alloantigens of stimulator cells, and by 72-96 $\mathrm{h}$ an expanding population of functional CTLs was generated. The survival rate of PK15/mIL18 cells was 1.5 -fold that of control cells (PK15 cells) but the survival rate of PK15/plL-18 cells was reduced (Figure 3 ). Therefore, the survival rates of $\mathrm{T}$ cell populations with PK15/mIL-18 or PK15/pIL-18 were increased versus the controls, and PK15/mIL-18 cells were protected by mouse $\mathrm{CD}^{+} \mathrm{T}$ cells.

\section{Stable porcine PK15 cells expressing IL-18 inhibited CTLs after cellular-xenograft}

We examined the effects of porcine IL-18 expression on the cytolytic activities of donor cells in mouse splenocytes. Splenocytes were harvested from C57BL/6 mice. Lymphocytes from these xenografted recipients were incubated with irradiated PK15, PK15/plL-18 or PK15/mIL-18 cells. IL-2 was added after 2 days of incubation to mouse splenocyte cultures. After 3 days of incubation, CTL activities were analyzed in lymphocyte media. Recently, it was reported that the incubation of mouse lymphocytes with irradiated PK15 cells and the addition of recombinant IL-2 on the third day of incubation, resulted in extensive proliferation and expansion of $\mathrm{CD}^{+}$cytotoxic $\mathrm{T}$ lymphocytes that were capable of

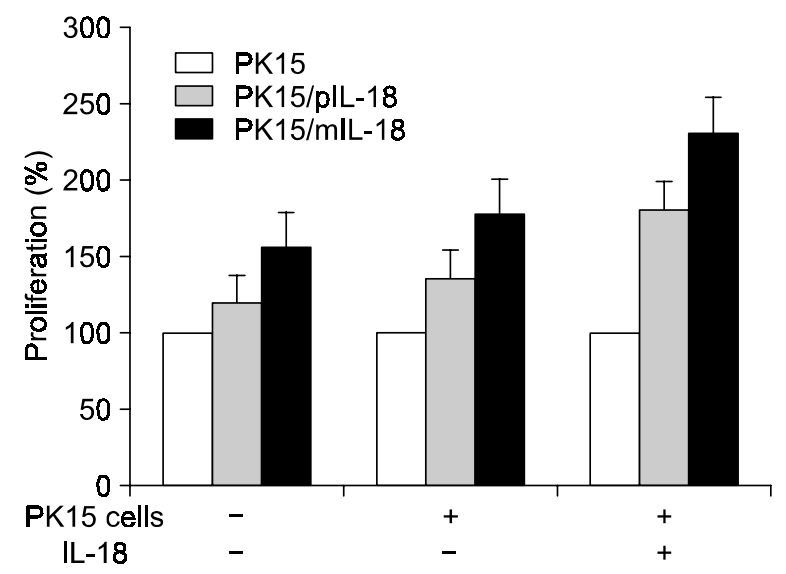

Figure 3. Effect of IL-18 overexpression on the proliferation of porcine kidney PK15 cells in primary mixed lymphocyte reactions (MLRs). Groups of splenocytes were plated at a density of $4 \times 10^{5}$ cells/well in RPMI 1640 supplemented with $10 \%$ FBS. C57BL/6 mice $(n=3)$ were injected with mouse recombinant IL-18 or PBS (control) for 10 days after xenografting. Splenocytes were harvested on day 40. PK15, PK15/plL-18 and PK15/mlL-18 cells were added into plates at a density of $4 \times 10^{5}$ cells/well. After 3 days of coculture with splenocytes, supernatants were harvested, and Th cell proliferations were measured using MTS assays. Experiments were done in triplicate, and values represent means $\pm S D$. 
directly killing xenogenic pig cells and normal and malignant cells from other species (Tanemura et al., 2002). $\mathrm{CD}^{+} \mathrm{T}$ cells can infiltrate xenografts and kill xenograft cells, which is the result of the extensive local activation and differentiation of $T$ cells into CTLs that kill target cells by a mechanism that does not involve the TCR complex. The Mashihiro group found that the relative contributions of cellular and humoral immune mechanisms mediating xenograft rejection may vary among recipients. Thus, both CTL and ADCC mechanisms have to be suppressed in the recipient to prevent xenograft rejection for prolonged periods of time. PK15/mIL-18 cells showed poor lytic activity against splenocytes (Figure 4). Our data shows that PK15/mIL-18 cells diminished the cytolytic activity of splenocytes.

\section{Comparisons of the phenotype patterns of recipient's cells in response to xenogenic PK15 vs PK15/plL-18}

We examined the effect of porcine IL-18 expression after xenogenic cell xenotransplantation. PK15 or PK15/plL-18 were injected into C57BL/6 mice, and animals were killed 2 weeks later and analyzed by two-color flow cytometry. Recently, several groups have reported that xenogenic cells were rejected within 10 days by an aggressive cell-mediated response in pig-to-baboon model (Fox et al., 2001). T cell responses to xenogeneic cells were not detected until day 2 post-transplantation, but were present at around day $5 . \mathrm{CD}^{+} \mathrm{T}$ cells exceeded $\mathrm{CD}^{+} \mathrm{T}$ cells in terms of xenogeneic responses but by day 5 there were as many $\mathrm{CD}^{+} \mathrm{T}$ cells, subsequently the levels of $\mathrm{CD}^{+}$and $\mathrm{CD} 8^{+} \mathrm{T}$ cells

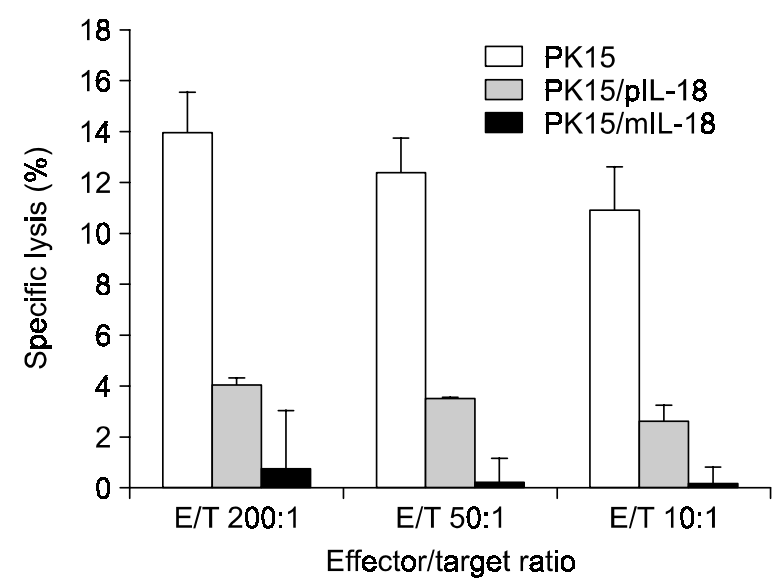

Figure 4. Suppression of CTL function after administering a cellular xenograft of PK15 cells expressing IL-18. Splenocytes from recipients were harvested and PK15, PK15/pIL-18 and PK15/mlL-18 cells were incubated for $96 \mathrm{hr}$ at $37^{\circ} \mathrm{C}$. After incubation, supernatants were counted using a $\beta$-counter. Experiments were done in triplicate, and values represent means $\pm S D$. decreased. After xenogenic cells had been rejected, we compared immune cell changes between PK15 and PK/plL-18. We identified the T cell population in mouse splenocytes using FITC conjugated Mo-Abs $\mathrm{CD}^{+}$. The resulting PK15 injected to C57BL/6 mice showed an increase in $\mathrm{T}$ cell population of about 20 percent, but little difference was observed between PK15 and PK15/plL-18 to C57BL/6 mice (Figure $5 A)$. However, lymph node cells in the PK15/ plL-18 injected to $\mathrm{C} 57 \mathrm{BL} / 6$ mice showed that a $\mathrm{CD} 3^{+} \mathrm{T}$ cell change, was decreased about 20 percent, as compared with PK15 cells, but the B cell population was increased in reverse proportion to $T$ cell. Thus, there was no difference in $T$ lymphocyte distribution patterns in spleen between control and PK15-treated or PK15/plL-18 treated mice. B cell numbers were elevated in lymph node whereas $T$ cells were attenuated in the lymph nodes of PK15/ plL-18 treated mice compared with control or PK15 treated mice.

\section{Distribution of $\mathbf{T}$ cell activation}

CD44, an adhesion molecule that mediates leukocyte attachment and homing to peripheral lymphoid organs and sites of inflammation, reduced in lymph node but did not reduce $T$ cell activation in splenocytes (Figure 5B). Moreover, a significant prolongation of islet allograft survival was noted in $\mathrm{CCR}^{-/-}$ recipients. This occurred in association with a reduction in the generation of $\mathrm{CD} 8^{+}$, but not of $\mathrm{CD} 4^{+}$ effector alloreactive $T$ cells (CD62L ${ }^{\text {low }} C D 44^{\text {high }}$ ) in $\mathrm{CCR}^{-/-}$compared with WT recipients (Reza et al., 2004). The $\mathrm{CD}^{+} \mathrm{T}$ cell population was high in mouse spleen, because in the normal group the proportion of $\mathrm{CD} 4^{+} \mathrm{T}$ cells to $\mathrm{CD} 8^{+} \mathrm{T}$ cells was 2 to 1 . Moreover, the ratio of $\mathrm{CD}^{+} \mathrm{T}$ cells to $\mathrm{CD} 8^{+} \mathrm{T}$ cells was altered in PK15 injected into mouse spleen and lymph node versus PK15/pIL-18. In particular, PK15/plL-18 injected mice had a low total percentage of $\mathrm{CD} 4^{+} \mathrm{T}$ cells in lymph nodes (Figure $5 \mathrm{C}$ ).

\section{Cytokine mRNA expression in mouse tissue after cellular xeno-transplantation}

Using real-time PCR, we examined the mRNA expression of different cytokines (IL-18 and IFN- $\gamma$ ) in mouse tissue from animals injected with PK15 or PK15/pIL-18 on day 14 after cell transplantation. IL-18 and IFN- $\gamma$ mRNA expression in seven tissues (liver, spleen, kidney, intestine, thymus, lung, and lymph nodes) from normal and non-transplanted control mice was also quantified. IL-18 (Figure 6A) and IFN- $\gamma$ (Figure 6B) mRNA transcripts were found in largest quantities in thymus and intestine in PK15 and PK15/pIL-18-injected mice, whereas PK15 and PK15/plL-18 injected mice showed low expression in 
A

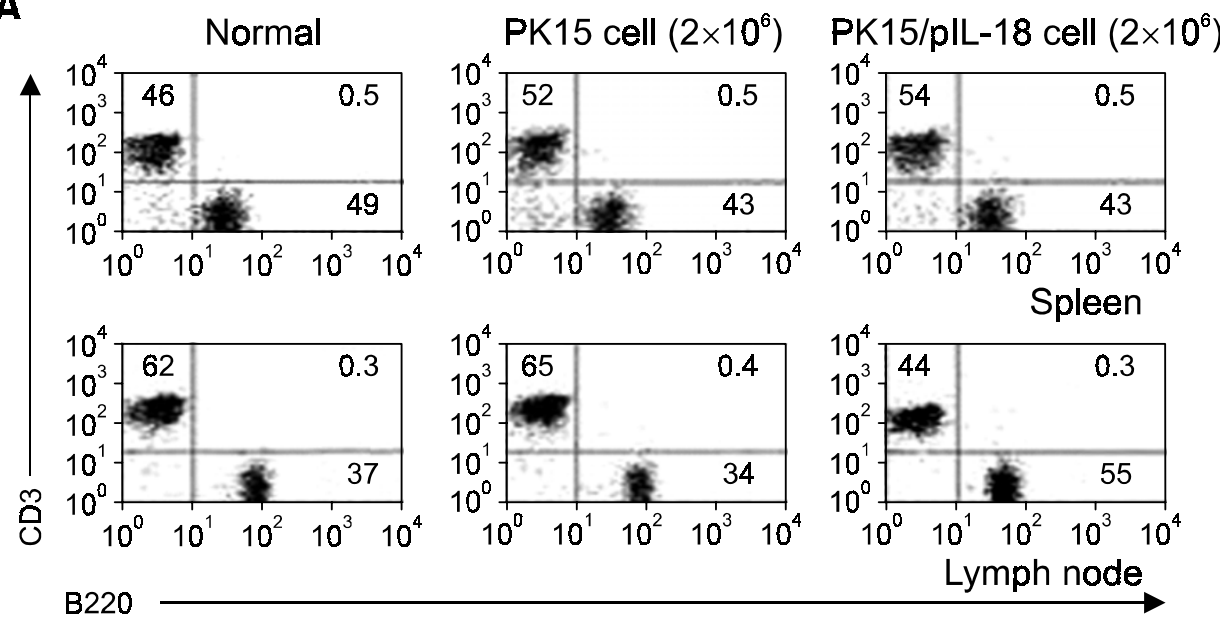

B
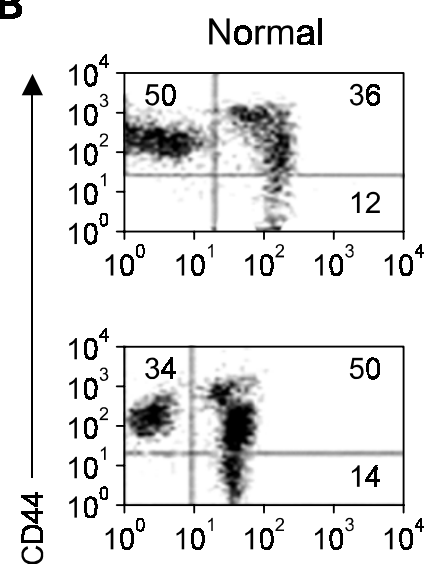

CD3

C
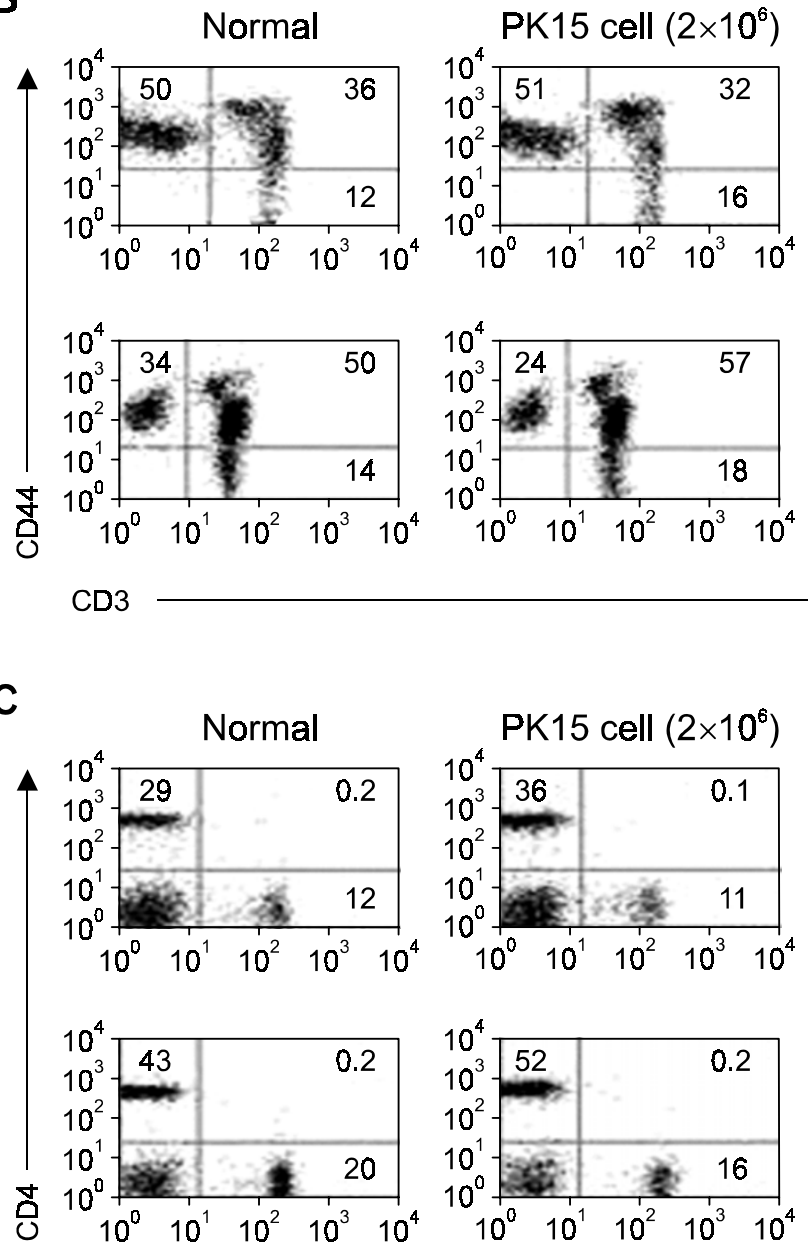

CD8

lymph nodes, as was the case in normal mice. In addition, IL-18 and IFN- $\gamma$ were up-regulated in the intestinal tissues from PK15/pIL-18-injected mice. In
PK15/plL-18 cell $\left(2 \times 10^{6}\right)$

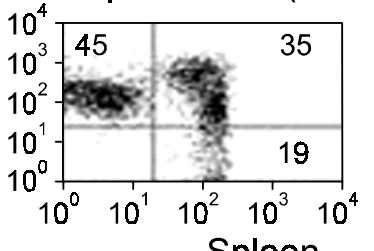

Spleen

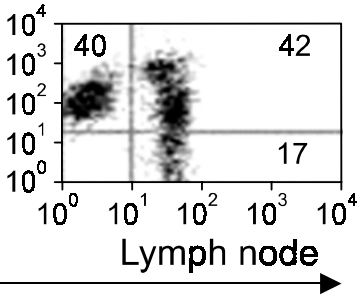

Figure 5. Distribution of lymphocytes in spleens injected with PK15 cells or PK15/plL-18 cells (A), distribution of activated T cells in mouse spleens and lymph nodes in response to PK15 and PK15/plL-18 cell treatments (B), and changes in $\mathrm{T}$ cell populations in mouse spleens and lymph nodes in response to PK15 and PK15/pIL-18 cell treatments (C); C57BL/6 mice were administered two i.v. injections of control (PBS), or of PK15 cells $\left(4 \times 10^{6}\right.$ cells $\left./ \mathrm{ml}\right)$ or PK15/plL-18 $\left(4 \times 10^{6}\right.$ cells $\left./ \mathrm{ml}\right)$ ( $n=3 /$ group). Mouse splenocytes were harvested after 14 days, and the phenotypes of splenic cell were determined by flow cytometry. Lymphocytes from spleens and lymph nodes were stained with anti-CD3 and anti-B220 antibodies (A), anti-CD3 and anti-CD44 antibodies (B) or anti-CD4 and anti-CD8 antibodies (C), respectively. contrast, cytokines were down-regulated in PK15injected mice. Small intestine findings indicate the potential role played by IL-18 as a means of first line 
A

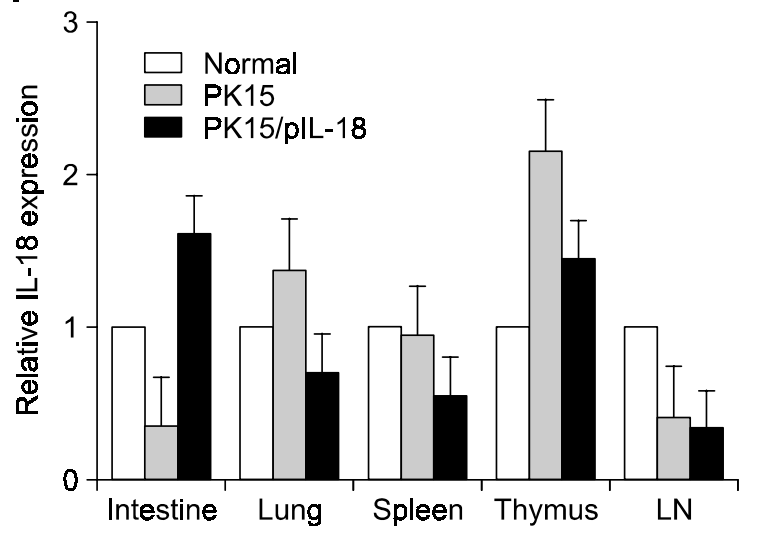

B

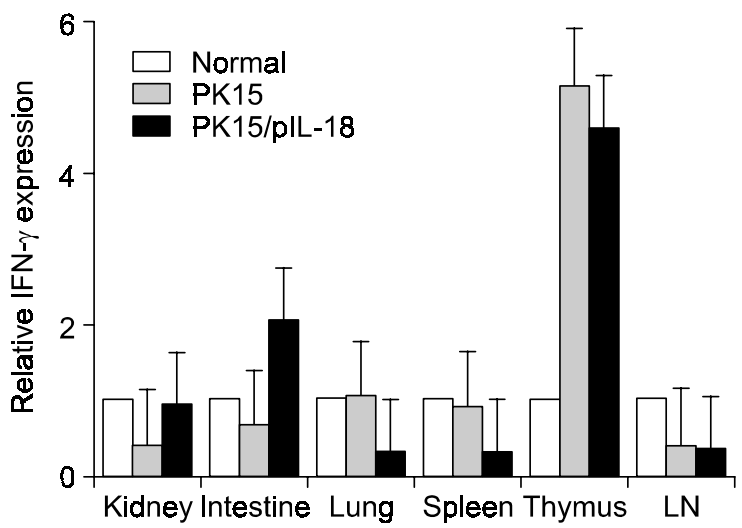

Figure 6. Expressions of IL-18 (A) and IFN- $\gamma(\mathrm{B})$ in the tissues of mice injected with PK15 or PK15/pIL-18 cells. IL-18 expression in the extraintestinal, lymphoid, and intestinal tissues of mice injected with PK15 or PK15/pL-18 cells. Mouse tissues were harvested after 14 days and homogenized. Total RNAs were isolated and assayed for IL-18, IFN- $\gamma$ and $\beta$-actin housekeeping gene expressions by real-time PCR. Graphs represent the absolute levels of mRNA ( $y$-axis) in different tissues ( $x$-axis). Experiments were performed in triplicate, and values represent means \pm SD.

host defense in the intestinal mucosa. Concordant cardiac mouse-to-rat xenotransplantation models show increases in pro-inflammatory cytokines, i.e., Th1-associated cytokines (IL-2, IFN- $\gamma$ and IL-12p40) and IL-10, and immunosuppression with CyA + DSG diminished the levels of all cytokines examined (Murase et al., 1993). Moreover, combining CyA with CVF markedly increased the amount of Th2-associated cytokines present in xenografts during long-term survival (Bach et al., 1997).

\section{Discussion}

It is important that the identities of immune suppression genes be determined because of their potential to reduce xenograft immune rejection. Moreover, the mechanism of cell-mediated xenograft rejection is only partially understood. Xenogenic cells are known to elicit $T$ cell responses that coincide with rejection, such as, the direct killing by $\mathrm{CD} 8^{+}$ $T$ cells of discordant xenografts. In particular, it is likely that the adjuvant innate immunity effects mediated by cytokines and chemokines impact many aspects of cells and contribute to the strength and complexity of xenograft rejection. Thus, we studied whether the expression of porcine IL-18 modulates T-cell-mediated xenoimmune response and delays rejection xenograft in PK15 cells.

In an in vivo experiment, the survival rates of populations with PK15/mIL-18 or PK15/pIL-18 were higher than those of control. Moreover, CTL reaction to the responder cells showed that PK15/mIL-18 cells diminished the cytolytic activities of recipient splenocytes.

In vivo, $\mathrm{CD}^{+} \mathrm{T}$ cells were found to be increased in mice injected with PK15 or PK15/pIL-18 cells but PK15/pIL-18 cell numbers were reduced in lymph nodes. Also, $\mathrm{CD} 8^{+} \mathrm{T}$ cell numbers were reduced in the lymph nodes of PK15/plL-18 injected mice, but the ratio of $\mathrm{CD}^{+} \mathrm{T}$ to $\mathrm{CD} 8^{+} \mathrm{T}$ cells were altered in PK15 injected mice in spleen and lymph nodes. Specifically, $\mathrm{CD} 4^{+} \mathrm{T}$ cells were activated rather than $\mathrm{CD}^{+} \mathrm{T}$ cells in spleen and lymph nodes of C57BL/6 mice, and the IL-18 transcript was weakly expressed in lymphoid tissue and highly expressed in intestine and thymus.

These results suggest that porcine IL-18 genes escaped destruction by mouse $\mathrm{CD}^{+} \mathrm{T}$ cells compared alone, and that porcine IL-18 regulated mouse anti-pig cellular rejection by escaping the host immune cells of xenotransplantation during the early phases of xenograft rejection.

\section{Acknowledgement}

This work was supported by grant No. R11-2002100-03006 from ERC program of the Korea Science \& Engineering Foundation.

\section{References}

Bach FH, Ferran C, Hechenleiter P. Accommodation of vascularized xenografts: expression of 'protective genes' by donor endothelial cells in a host Th2 cytokine environment. Nat Med 1997;3:196-203

Barth RN, Yamamoto S, LaMattina JC, Kumagai N, Kitamura H, Vagefi PA, Awwad M, Colvin RB, Cooper DK, Sykes M, Sachs $\mathrm{DH}$, Yamada K. Xenogeneic thymokidney and thymic tissue transplantation in a pig-to-baboon model: evidence for pig-specific T-cell unresponsiveness. Transplantation 2003; 75:1615-24 
Cascalho M, Platt JL. Xenotransplantation and other means of organ replacement. Nat Rev Immunol 2001;1:154-60

Cho D, Song H, Kim YM, Houh D, Hur DY, Park H, Yoon D, Ptun KH, Lee WJ, Kurimoto M, Kin YB, Kim YS, Choi I. Endogenous interleukin-18 modulates immune escape of murine melanoma cells by regulating the expression of Fas ligand and reactive oxygen intermediates. Cancer Res 2002;60:2703-9

Chomczynski P, Sacchi, N. Single-step method of RNA isolation by acid guanidinium thiocyanate-phenol-chloroform extraction. Anal Biochem 1987;162:156-9

Fox A, Mountford J, Braakhuis A, Harrison LC. Innate and adaptive immune responses to nonvascular xenografts: evidence that macrophages are direct effectors of xenograft rejection. J Immunol 2001;166:2133-40

Hartig CV, Haller GW, Sachs DH, Kuhlenschmidt S, Heeger PS. Naturally developing memory $T$ cell xenoreactivity to swine antigens in human peripheral blood lymphocytes. J immunol 2000;164:2790-6

Hill GR, Cooke KR, Teshima T. Interleukin 11 promotes T cell polarization and prevents acute graft-versus-host disease after allogenic bone marrow transplantation. J Clin Invest 2001;102:115-23

Holler E. Cytokines, virus, and graft-versus-host disease. Curr Opin Hematol 2002;9:479-84

Lorant T, Krook H, Wilton J, Olausson M, Tufveson G, Korsgren $\mathrm{O}$, Johnssson $\mathrm{C}$. Ingrafts cytokine mRNA expression in rejecting and non-rejecting vascularized xenografts. Xenotransplantation 2003;10:311-24
Muneta Y, Mori Y, Shimoji Y, Yokomizo Y. Porcine interleukin 18: cloning, characterization of the cDNA and expression with the baculovirus system. Cytokine 2002;12:566-72

Murase N, Starzl TE, Demetris AJ. Hamster-to- rat heart and liver xenotransplantation with FK506 plus antiproliferative drugs. Transplantation 1993;55:701-11

Nakanishi K, Yoshimoto T, Tsutsui H, Okamura H. Interleukin-18 regulates both Th1 and Th2 responses. Annu Rev Immunol 2001;19:423-74

Oem JK, Song HJ, Kang SW, Jeong WS. Cloning, Sequencing, and expression of porcine interleukin-18 in Escherichia coli. Mol Cells 2000;10:343-7

Ohtsuki T, Micallef MJ, Kohno K, Tanimoto T, lkeda M, Kurimoto M. Interleukin 18 enhances Fas ligand expression and induces apoptosis Fas-expressing human myelomonocytic KG-1 cells. Anticancer Res 1997;17:3253-8

Reza A, Terry KM, Toshiro I, Rex NS, Nader N, Mollie J, Vaja T, Israel C, Hugh A, Mohamed HS, Andrew DL. Differential role of CCR2 in islet and heart allograft rejection: tissue specificity of chemokine/chemokine receptor function in vivo. J immunol 2004;172:767-75

Tanemura M, Chong AS, Disesa VJ, Galili U. Direct killing of xenograft cells by $\mathrm{CD}^{+} \mathrm{T}$ cells of discordant xenograft recipients. Transplantation 2002;74:1587-95

Zhan Y, Brady JL, Irawaty W, Thomas HE, Kay TW, Lew AM. Activated macrophages require $T$ cells for xenograft rejection under the kidney capsule. Immunol Cell Biol 2003;81:451-8 